\title{
Qualitative study of stigmatization of mental illness in the Japanese workplace: The experience of mentally disabled people
}

\author{
Hatsumi Yoshii \\ Faculty of Medicine, School of Health Sciences, Tohoku University, Miyagi, Japan; hatsumi@med.tohoku.ac.jp
}

Received 30 April 2013; revised 30 May 2013; accepted 15 June 2013

Copyright (C) 2013 Hatsumi Yoshii. This is an open access article distributed under the Creative Commons Attribution License, which permits unrestricted use, distribution, and reproduction in any medium, provided the original work is properly cited.

\begin{abstract}
I examine stigmatization of mental illness in the Japanese workplace. The participants were 25 Japanese adults with mental disorders who were interviewed regarding their experience of stigmatization in places they had worked. Narrative data from semi-structured interviews were analyzed qualitatively. Responses were classified as stigma toward treatment, stigmatizing attitudes, and stigmatization due to disclosure of illness, and the characteristics of stigmatization experienced by people with mental disorders were identified. The findings, in conjunction with analysis of anti-stigma programs worldwide, are expected to contribute to the development of effective anti-stigma measures in Japan.
\end{abstract}

Keywords: Stigma; Mental Disease; Workplace

\section{INTRODUCTION}

Stigmatization of the disabled person is now a focus in the medical treatment and welfare of people with mental disorders [1-3]. Stigma has been defined as a "negative evaluation imposed by those in the majority in society upon those individuals or groups who possess different characteristics from them [4]." The existence of stigma toward people with mental disorders has been noted by Angermeyer [5] and is a major obstacle to achieving a society where those with and without disabilities work together. The three principal reasons for stigmatization of those with mental disorders are a feeling of danger deriving from their incomprehensible actions, a vision of them as unable to participate normally in society, and misunderstanding of their disorder [6]. In other words, people with mental disorders are stereotyped as dangerous people who are unpredictable, aggressive, and might be connected with violence and crime. Their human rights might thus be regarded as less important due to their being seen as "social derelicts", incapable of functioning properly in society. These two stereotypes likely arise from a third problem: misunderstandings due to insufficient knowledge of mental disorders. Stigmatization has a complex influence upon mentally disabled people [7]. When their condition is discovered, many suddenly find themselves alienated from peers and superiors, which may cause feelings of victimization and self-loathing. Therefore, people with mental disorders suffer even more as a result of a vicious cycle of rejection and prejudice toward people with mental disorders. This situation can lead to conditions that further obstruct recovery from illness, including social isolation, loss of employment, alcohol dependence, illicit drug use, homelessness, and unnecessary residence in welfare facilities [8].

In Japan, the responsibility placed upon companies to hire people with mental disorders has gradually increased, and this has led to a need for strategies to address stigmatization in the workplace. A study of trends in and outside Japan analyzed workplace stigmatization of those with mental disorders [9]. However, much of that research focused on the responses of company presidents and owners and did not collect data from those with mental disabilities. The study concluded that further studies of workplace stigmatization of people with mental disorders were necessary, and that there was a need to establish an organizational support system that would facilitate development of strategies to address workplace stigmatization. In light of previous findings, and to develop strategies for addressing workplace stigmatization of those with mental disorders, the present study focused on workplace stigmatization as experienced by people with mental disorders. The principal aim was to determine the actual characteristics of such stigmatization. Any attempt to analyze workplace stigmatization of people with mental disorders and develop strategies to address such stig- 
matization cannot ignore the accounts of those most affected. To define the problem of workplace stigmatization of people with mental disorders, the author conducted and analyzed interviews of people with mental disorders discussing their workplace experiences. Stigmatization is an important issue in mental health and welfare, a field that attempts to address both the illness characteristics of those with mental disorders and its influence on their ability to continue working. The present study was conducted to encourage development of strategies that address workplace stigmatization of people with mental disorders.

\section{METHODS}

\subsection{Participants}

The interviewees in the present study were all associated with mental health care support facilities in the same prefecture. The facility was either a mental health daycare facility, regional living assistance center, or a B-type employment assistance office. The participants had all received a diagnosis of schizophrenia, depression, and/or manic disorder.

\subsection{Ethical Considerations}

Approval to conduct this research was obtained from the Graduate School of Medicine, Tohoku University, Japan. The participants were told that the content of the investigation would be used for research only, that they could withdraw from the study at any time, that their participation would be kept confidential, and that all data would be handled anonymously. Each interviewee signed an informed consent form before participating in the study.

\subsection{Procedure}

All participants were formally interviewed at their respective facilities, and the interview generally followed a pre-established format, starting with the general question, "What kind of stigma have you experienced at your workplace?" The questionnaire then proceeded to more specific questions, such as "Why did you leave your former place of employment?" and "In retrospect, how do you feel about having told your coworkers and/or your boss about your condition?" Each interview lasted 1 hour, and interviews were tape-recorded with the participants' permission.

\subsection{Analytical Methods}

The content of the interviews was transcribed word-forword, after which the raw data were coded according to context, and each code was categorized according to their common characteristics. Subcategories were then extracted from the material with reference to reasons for workplace stigmatization, and these subcategories were then classified into more-abstract ideas, which were analyzed using Atlas.ti.7.0 (Scientific Software Development GmbH, Berlin).

\section{RESULTS}

\subsection{Sample Characteristics}

Interviews were conducted with 25 participants: 16 men and 9 women (Table 1). By age, the largest group of participants $(n=11)$ was those in their $40 \mathrm{~s}$. The most common disorder $(n=16)$ was schizophrenia. Fifteen of the participants attended a mental health daycare facility.

\subsection{Workplace Stigmatization of People with Mental Disorders (Table 2)}

The codes referring to workplace stigmatization of those with mental disorders were extracted and classified into 17 subcategories. These subcategories were then classified into three higher-level categories: stigma toward

Table 1. Interviewee demographics $(n=25)$.

\begin{tabular}{lc}
\hline Characteristic & $\mathbf{n}$ \\
\hline Gender & \\
Male & 16 \\
Female & 9 \\
Age, $\mathbf{y}$ & \\
20 - 29 & 1 \\
30 - 39 & 3 \\
40 - 49 & 11 \\
50 - 59 & 3 \\
60 - 69 & 5 \\
70 - 79 & 2 \\
Education & \\
High school & 17 \\
Vocational school & 4 \\
Junior college & 1 \\
University & 3 \\
Mental disorder & \\
Schizophrenia & 16 \\
Depression & 2 \\
Mania & 2 \\
Manic-depression & 1 \\
Personality disorder & 7 \\
Obsessive-compulsive neurosis & 2 \\
Institution & 1 \\
Mental health daycare facility & 1 \\
Regional living assistance center & \\
B-type employment assistance office & 1 \\
\hline & \\
\hline
\end{tabular}


Table 2. Workplace stigmatization of people with mental disorders.

\begin{tabular}{|c|c|}
\hline Categories & Subcategories \\
\hline \multirow[t]{7}{*}{ Stigma toward treatment } & Finding it impossible to get hired \\
\hline & Not being hired or being fired because of illness \\
\hline & Hired with substandard salary \\
\hline & Unacceptable workplace transfers \\
\hline & Not understanding the reason for dismissal \\
\hline & Quitting when asked about intention to continue working upon return from hospital \\
\hline & Release due to symptoms \\
\hline \multirow[t]{8}{*}{ Stigmatizing attitudes } & Harsh words from superiors and/or coworkers \\
\hline & Coworkers shocked when told of illness \\
\hline & "No one would tell me what to do at the workplace I was transferred to" \\
\hline & Unreasonable treatment in the workplace \\
\hline & Not knowing the reason for unreasonable treatment \\
\hline & Prejudice against people with disabilities \\
\hline & Not disclosing an illness after seeing poor treatment of other people with disabilities \\
\hline & Lack of concern for people with mental disorders \\
\hline Stigmatization due to disclosure of illness & Disadvantages of disclosing a mental disorder \\
\hline
\end{tabular}

treatment, stigmatizing attitudes, and stigmatization due to disclosure of illness. Each category is explained below.

\subsubsection{Stigma toward Treatment}

It was virtually impossible for participants to obtain employment: most were either fired or not hired as a result of their disorder. Furthermore, participants who were hired had to agree to substandard wages. Some experienced unacceptable workplace transfers, and some did not know why they were fired. They also experienced "unreasonable firing or rejection." Upon their return after hospitalization, a few participants quit work after being asked if they intended to continue working at the company. Some were fired due to their symptoms. Some did not reveal their condition to others in their workplace, but their mental condition worsened as they continued to work and they eventually did not receive their salary and were fired. Examples of answers obtained from participants appear below.

1) Finding it impossible to get hired

"I had many job interviews, but failed them all. I failed no matter where I went. Then my guardian said to me, "Don't worry, you'll definitely qualify for public assistance." So I thought, well, in that case, from now on I'll do volunteer work."

2) Not being hired or being fired because of illness

Q: Was there no difference in your working style before you started seeing strange things and later when you were an outpatient and seeing strange things?

A: Well, my memory got bad.

Q: Did others ever warn you about this?

A: Yes.
"My writing is messy because my hands are shaking a little. My condition has gradually gotten worse."

3) Hired with substandard salary

"I received around 100,000 yen a month. I worked in the cafeteria from 10 AM to 9 PM for 100,000 yen [a month]. There was no bonus."

Q: Did you feel that amount was acceptable? Didn't you think, "It would be nice if I could get more"?

A: No, I didn't think so. I was already receiving a survivor's pension, and I'd accepted that I would be working in the cafeteria for 100,000 yen.

4) Unacceptable workplace transfers

"When I was 54 years old, I started having symptoms of depression, and so I was admitted and then released from the hospital a total of six times in 1 year. I was summarily sent by my company to another department. Until then, because I was in management, my job was just pen-pushing, but my new job involved carrying heavy stuff. The atmosphere at my new position was such that I didn't feel I should complain about it. I hurt my back and gradually started to hate having to go to work. I clearly said, 'I want to return to management.' However, I was told, 'This is the only work we can give you. It's this or nothing.' I couldn't accept what they were telling me. If only I hadn't been transferred, I probably would've been able to keep working until retirement."

"I was always working in sales management, but I quit my company when I was 45 years old. I was absent without notice. Although it might have been okay if I had just made a single phone call, I didn't call. That day, for some reason I just felt like not going to my company. Then, the next day, when I went to work I was transferred, and 
stuck doing general work. I put up with this for 10 days, but then I thought, "I can't take this anymore." And no one would tell me what to do at my new job. In the final analysis, I bet this was a way of "restructuring me."

Q: Did you say "please don't transfer me" to your boss?

A: No, I didn't.

Q: Why?

A: I couldn't because I didn't want my boss to ask me, "Why were you absent without notice?" in front of the other workers.

"Even though my boss said "we'll wait for you" at the start of my period off work, when I came back, my chair was gone. When I got back from my time off, I saw all my things had been put away and that my name was not on the list of workers anymore. When I asked my boss about this, I was told, "You have a job, what's your problem?" While I was gone, my desk had been moved away from others, and my job responsibilities had been completely changed, too."

5) Not understanding the reason for dismissal

"I was fired. I don't know why I was fired. My coworkers tried to start fights with me: why should it be me who was fired?"

6) Unreasonable dismissal/non-hiring

"When I told the store manager, "I'm taking tranquillizers," I was told, "If you're taking tranquillizers, don't come." When my parents called the manager to say, "Please don't fire him," they were told, "I don't even want to see him again." I was working there for only 2 months. My release was formally registered as having been my decision to quit."

"The interviewer took one look at me and immediately said, 'You're not getting the job."'

....

"I was released due to their attitude that "unstable people aren't welcome here," and quit without receiving my December paycheck."

7) Quitting when asked about intention to continue working upon return from hospital

“After I came back to work, I couldn't really fit back into the company. When I was asked, 'What are you going to do?' by my boss, I just quit the company."

8) Release due to symptoms

"I got a little sick while I was working at a printing company. I was fired because I was unstable."

\subsubsection{Stigmatizing Attitudes}

The participants received harsh words from their superiors and coworkers. In addition, coworkers were taken aback when participants disclosed their illness. Some participants were not given instructions regarding what to do at a new workplace. Many participants were treated unreasonably at work and did not understand the reasons for this. The participants felt that they were regarded as "the handicapped one" at their workplace. Also, when some of the participants saw the terrible way other people with disabilities had been treated, they were afraid to reveal their own illness. Participants felt that nobody cared about their psychological illness at work. Examples of answers collected from the interviewees are shown below.

1) Harsh words from superiors and/or coworkers

"People around me spoke to me very coldly. My boss said some terrible things to me."

"I was told, 'Just be happy you have a job' by my boss."

2) Coworkers shocked when told of illness

"One year after I started to get sick, when I told my coworkers about my illness everybody was surprised. And my coworkers said, 'You'd better keep it hidden."'

3) "No one would tell me what to do at the workplace I was transferred to"

"After I was released from hospital, I returned to the repair shop, but I became uncomfortable, so I quit. After 3 months, it had become uncomfortable to go to work, because no one would tell me what I had to do. In the repair shop, if no one tells me what to do, I can't work. I didn't have any tools I can use, and no one would tell me what to do, so I became uncomfortable there and quit."

Q: Did they used to tell you what to do before you entered the hospital?

A: Yes, they told me.

Q: I wonder why they suddenly stopped telling you what to do?

A: I don't know.

"They changed my job, but they didn't give me any instructions about what to do there. After being transferred to my new position, I wish there had been a system to clearly tell me the details of what I had to do-and that they hadn't just thrown me into this new place. If there had been such a system, I might have been able to continue working there. I was just left alone, you know? I didn't know what to do."

4) Unreasonable treatment in the workplace

"When one of the people in the office went out, he forgot to bring his cell phone. He should have been reprimanded, but it was made to be my fault."

"Even when another worker came and kicked me, I didn't tell anyone because I'm cowardly. I just lost any interest in working anymore." 
"There was a plan that I should work an extra hour overtime. However, the day before I was told, "You look so uncomfortable, so we don't want you to work that extra hour." I thought that was strange, so I quit. Without my knowledge, someone had reported my condition to my boss."

5) Not knowing the reason for unreasonable treatment

Q: Why did you receive unreasonable treatment?

A: Honestly, I don't know. I don't know why I received this kind of unreasonable treatment.

6) Prejudice against people with disabilities

"The interviewer had already decided that people with disabilities were only able to do simple tasks. But there are people with disabilities who can work well."

7) Not disclosing an illness after seeing poor treatment of other people with disabilities

"At work, there was a worker who had seizures and another who had cognitive impairments. My other coworkers were completely two-faced to them. In other words, they were kind to them to their face but said terrible things about them behind their backs. When I saw this, I thought I'd better not reveal my illness."

8) Lack of concern for people with mental disorders

"Nobody ever asked me, "What kind of illness is it?",

"They have absolutely no knowledge about my illness. They don't ask about it or listen to me. There was not a single question from my boss about it. I'd like them to know that it's possible to control my symptoms with medication or by going to the hospital. I don't want them just to hire me without asking me about things that might be difficult."

"I was never asked anything about my illness by the people at work."

\subsubsection{Stigmatization Due to Disclosure of Illness}

Disclosing an illness was very disadvantageous for many participants. Examples of participant responses are shown below.

Disadvantages of disclosing a mental disorder

"I had interviews at 15 places, but not a single one hired me, probably because I'm a person with a mental disability. I tried for jobs such as a 5-hour part-time job, and even only a 1-hour cleaning job, but wasn't hired for any of them."

"When I said that I had a mental illness, everybody started looking at me strangely, so I quit. When I told my coworkers that I'd been in the hospital for my mental disorder, they looked at me weirdly. I felt that people avoided me after I revealed my illness to them. When I talked about my illness at job interviews, I never got the job."

\section{DISCUSSION}

The population of Japan began to decline in 2005. It is likely that the birth rate will continue to decline and that the average age of the population will continue to rise. There have been predictions of a much lower population in the not-too-distant future [10]. If strategic measures to increase employment are not implemented, and 2006 employment rates continue at the same levels, the workforce will decrease to approximately $10,700,000$ in 2030 . Such a large diminution in the Japanese workforce would severely limit supply in the economy. Therefore, economic growth in general, and demand as well, would be greatly affected [11]. To avoid such economic problems, strategies that encourage employment (e.g. regional-production employment strategies and strategies for equal employment opportunities for men and women) are being put in place, and implementation of other employment promotion strategies has helped increase the numbers of youth, disabled people, foreign workers, and seniors in the workplace. Employment of disabled people in particular was addressed by enactment of the Services and Supports for Persons with Disabilities Act and other strategies for increasing economic growth implemented by the Japanese government, as the movement away from "welfare and care services" toward "employment and independence" gains momentum. In 1976, revision of the Physically Handicapped Persons Employment Promotion Law led to the introduction of employment quotas for people with disabilities. Starting in 1983, the United Nations Decade of Disabled Persons proclaimed the idea of normalization, expressed as "full participation and equality" for disabled people. As a result of these programs, the numbers of employed disabled people began to increase every year, and in a larger variety of fields as well [12]. However, a careful examination of changes in actual employment rates since the Japanese government began to promote and subsidize employment of disabled people shows that, while such employment rates have continued to improve every year in large companies (defined as $\geq 300$ employees), actual employment rates in medium and small enterprises $(<300$ employees $)$ have been decreasing during the last 10 - 20 years [12]. In 2012 , only $46.8 \%$ of all Japanese enterprises met quotas for employment of disabled people, demonstrating their reservations regarding such quotas and unwillingness to participate in them [12]. The total number of people with mental disorders employed in 2012 was 16,607 (as registered by companies with $\geq 56$ employees), which compares poorly with employment figures for those with cognitive impairments (74,743 employed) and those with physical disabilities (291,013.5) [12]. This discrepancy may be because, of these three types of disability (psychological, cognitive, and physical), those with mental disorders were not mentioned in quotas for disability hir- 
ing practices. However, this situation is being remedied and advances are being made, as reflected in revisions to the Law for Employment Promotion of Persons with Disabilities and other efforts to develop and improve employment strategies for people with mental disorders. The numbers of such people leaving vocational facilities and seeking employment in the ordinary workplace are much higher than the numbers of people with cognitive impairments or physical disabilities [13]. However, this study revealed that commonly recurring themes (subcategories) could be extracted from the interviews-such as, "I find it very difficult to get hired," "I was fired (not hired) because of my illness," and "I was fired (not hired) on unreasonable grounds"- that indicate that people with mental disorders may find it very difficult to get past the hiring process. These results provide further confirmation of the general theory of Brohan [13], which suggests that people with psychological disabilities might actively reject the opportunity to work, or actually stop looking for work, in anticipation of prejudice toward them.

The improved productivity of people with mental disorders, the economic incentives to companies that employ them, and increases in personal revenue of people with mental disorders might reduce public assistance payments and other social security costs, thereby alleviating the burden on individual taxpayers. To this end, it will be necessary to further increase employment and hiring rates of people with mental disorders. However, in the present study, one participant revealed that she was made to work for low wages and was not hired as someone with a mental disorder. She worked 10 hours every day, without a day off, and received a monthly salary of 100,000 yen. This does not satisfy the requirements of the Labor Standards Law with respect to wages and employee treatment. Furthermore, another participant was successfully hired and was working, but when the participant's illness was discovered, the participant's superiors and coworkers became unfriendly, and mistakes due to the illness became the cause for the participant's dismissal. Similarly, many other people with mental disorders were released due to their illness or related problems. The present findings are very similar to those of Michalak et al. [14], who interviewed people with bipolar disorder, among whom half reported experiences of workplace stigmatization. In the present study, as well, many participants reported dismissal, loss of promotion opportunities, and de facto demotion when they revealed that they had a mental disorder. Similarly, when their illness was discovered, participants experienced prejudicial attitudes from their superiors and coworkers, reduced opportunities for promotion, and mistaken inferences and gossip by others regarding their condition, as well as general rejection and social alienation.

In Japan, the legal responsibility of companies to hire people with mental disorders has gradually increased. Given the present unfavorable state of the economy, companies must continue to show a profit even as they hire an increasing number of people with mental disorders, which underlines the necessity of establishing various strategies that support the employment of people with mental disorders. The present results indicate that these strategies should involve eliminating or reducing workplace stigmatization of people with mental disorders. Presently, in accordance with the Law for Employment Promotion of Persons with Disabilities, regional job centers for people with disabilities (47 centers nationwide), "Hello Work" employment centers (591 nationwide), and employment and life support centers for people with disabilities (110 centers nationwide) offer employment assistance services to people with mental disorders, as well as counseling and advice. These centers even offer job placement and other services. The productivity and general ability to work of people with mental disorders can depend on their environment and the attitudes of coworkers [13]. Thus, as their coworkers acquire a correct understanding of their illness, with appropriate use of technology, their productivity and efficiency will continue to increase. However, in a literature review, Bender et al. [15] reported that people with depression experienced workplace stigmatization, worried that their coworkers would never be able to understand their illness, and were reluctant to seek professional help due to their privacy concerns. The present study identified the following recurrent subcategories in participant interviews: "when I told my colleagues about my illness, they were shocked," "lack of interest in my illness," and "prejudice towards people with disabilities." These recurring themes reveal the importance of their coworkers' fundamental attitude toward psychological illness in general, even before having real knowledge of it. Another literature review, by Laxman et al., [16] investigated the situation of people with borderline personality disorders in North America and found that their careers were severely impeded by the experience of workplace stigmatization and dismissal, delayed promotion, and even demotion, together with a variety of other related obstacles. The present findings are similar to theirs in that the author identified subcategories such as "unacceptable transfers and postings" and "quitting when I was asked if I intended to continue working, or quitting when I returned to my workplace."

The present study is the first in Japan to report on workplace stigmatization as experienced by people with mental disorders. The results seem to reflect the particular characteristics of the Japanese population, as indicated by responses such as "I don't know why I was fired," "I don't know why my superiors and coworkers treated me unreasonably," "I kept my condition secret when I saw the terrible way other people with similar 
conditions were treated," "when I arrived at the place I'd been newly transferred to, no one would tell me what I had to do there," and "unkind words from superiors and colleagues." All of these seemed to arise from characteristics particular to Japanese culture, such as a reluctance to ask for explanations and self-restraint. However, the results of the present study also have many points in common with those of studies done elsewhere. This suggests that strategies used to address workplace stigmatization in other countries could be similarly effective in Japan. The present results can be used as a basis for developing strategies and evidence-based approaches to address workplace stigmatization. In recent years, the results of various strategies implemented to deal with stigmatization have been published in countries other than Japan [17-19]. These "anti-stigma strategies" are increasing awareness and interest of such strategies in Japan, as evidenced by the creation of a Japanese research society on this topic, among other developments. However, it cannot be said that sufficient content and methods have been developed for evidence-based strategies to deal with workplace stigmatization in Japan. The present study increases our understanding of the realities of workplace stigmatization, as experienced by those with mental disorders, and makes an important contribution toward development of necessary strategies to allow people with mental disorders to continue working in society even as they receive treatment for their illness. The author hopes that the present results will assist in developing strategies that improve mental health care and welfare here in Japan.

\section{STUDY LIMITATIONS}

Most of the participants are not currently working. Therefore, the present study was unable to analyze problems encountered by persons with mental disorders when restarting work.

\section{ACKNOWLEDGEMENTS}

This work was supported by a 2013 The Uehiro Foundation on Ethics and Education, entitled "The Problem of Stigma toward People with Mental disorder in the Workplace".

\section{REFERENCES}

[1] Chou, K.C., Esterberg, M.L., Compton, M.T., McGee, R., Shim, R. and Hochman, K. (2002) Knowledge about schizophrenia and social distance toward individuals with schizophrenia: A survey among predominantly low-income, urban, African American community members. Journal of Psychiatric Practice, 14, 86-93.

[2] Lysaker, P.H., Davis, L.W., Warman, D.M., Strasburger, A. and Beattie, N. (2007) Stigma, social function and symptoms in schizophrenia and schizoaffective disorder: Associations across 6 months. Psychiatry Research, 149, 89-

\section{5. doi:10.1016/i.psychres.2006.03.007}

[3] Corrigan, P.W., Green, A., Lundin, R., Kubiak, M.A. and Penn, D.L. (2001) Familiarity with and social distance from people who have serious mental illness. Psychiatric Services, 52, 953-958. doi:10.1176/appi.ps.52.7.953

[4] Tanaka, G., Inadomi, H., Kikuchi, Y. and Ohta, Y. (2004) Evaluating stigma against mental disorder and related factors. Psychiatry Clinical Neuroscience, 58, 558-566. doi:10.1111/j.1440-1819.2004.01300.x

[5] Angermeyer, M.C. and Matschinger, H. (1997) Social distance towards the mentally ill: Results of representative surveys in the federal Republive of Germany. Psychological Medicine, 27, 131-141. doi:10.1017/S0033291796004205

[6] Yoshii, Y. (2009) Factors Contributing to the stigma of mentally disabled: Reading previous studies. Journal of Japan Academy of Psychiatric and Mental Health Nursing, 18, 140-146.

[7] Stuart, H. (2006) Reaching out to high school youth: The effectiveness of a video-based antistigma program. Canadian Journal of Psychiatry, 51, 647-653.

[8] Gaebel, W., Zaske, H., Baumann, A.E., Klosterkotter, J., Maier, W., Decker, P. and Moller, H.J. (2008) Evaluation of the German WPA "Program against stigma anddiscrimination because of schizophrenia-Open the doors": Results from representative telephone surveys before and after three years of antistigma interventions. Schizophrenia Research, 98, 184-193. doi:10.1016/j.schres.2007.09.013

[9] Yoshii, H. (2012) The problem of stigma toward people with mental disorder in the workplace. Japan Society for Occupational Mental Health, 20, 135-141.

[10] Cabinet Office, Government of Japan. http://www.cao.go.jp/

[11] Ministry of Internal Affairs and Communications. http://www.stat.go.jp/index.htm

[12] Ministry of Health, Labour and Welfare. http://www.mhlw.go.jp/stf/houdou/2r9852000002o0qm-at t/241114houkoku.pdf

[13] Brohan, E. and Thornicroft, G. (2010) Stigma and discrimination of mental health problems: Workplace implications. Occupational Medicine (Lond), 60, 414-415. doi:10.1093/occmed/kqq048

[14] Michalak, E.E., Yatham, L.N., Maxwell, V., et al. (2007) The impact of bipolar disorder upon work functioning: A qualitative analysis. Bipolar Disorder, 9, 126-143. doi:10.1111/j.1399-5618.2007.00436.x

[15] Bender, A. and Farvolden, P. (2008) Depression and the workplace: A progress report. Current Psychiatry Reports, 10, 73-79.

[16] Laxman, K.E., Lovibond, K.S. and Hassan, M.K. (2008) Impact of bipolar disorder in employed populations. American Journal of Managed Care, 14, 757-764.

[17] Agrest, M.V. (2011) Users' participation in mental health services. 22, 409-418.

[18] Kermode, M., Bowen, K., Arole, S., Pathare, S. and Jorm, A.F. (2009) Attitudes to people with mental disorders: A 
mental health literacy survey in a rural area of Maharashtra, India. Social Psychiatry and Psychiatric Epidemiology, 44, 1087-1096. doi:10.1007/s00127-009-0031-7

[19] Hamilton, L.A., Aliyu, M.H., Lyons, P.D., May, R., Swan- son Jr., C.L., Savage, R. and Go, R.C. (2006) AfricanAmerican community attitudes and perceptions toward schizophrenia and medical research: An ploratory study. Journal of the National Medical Association, 98, 18-27. 